\title{
APPLICATION OF SYSTEM IDENTIFICATION TECHNIQUES TO TEJAS FLIGHT TEST DATA
}

\author{
Jatinder Singh $^{\dagger}$, Amitabh Saraf ${ }^{\#}$, Vijay Patel ${ }^{\#}$, Basappa $^{\dagger}$ and Sachin Tharewal ${ }^{\dagger}$
}

\begin{abstract}
Tejas, the Indian Light Combat aircraft, is a fly-by-wire aircraft with relaxed longitudinal stability that provides for enhanced agility, high maneuverability and performance. The aircraft is presently undergoing extensive flight test trails and the flight data gathered is being used by various design groups to evaluate aircraft systems, performance and aerodynamic characteristics. This paper gives an overview of the application of system identification techniques to Tejas flight test data for validation and update of the aircraft aerodynamic database. The aerodynamic characterization is carried out using two different approaches i) point model identification, and ii) coefficient level matching. Typical results are presented from both the approaches along with the time history plots from the flight updated aero database. The main purpose of this paper is show to how system identification techniques can lead to accurate determination of aerodynamic characteristics from flight test data.
\end{abstract}

Key Words: Flight testing, flight data, parameter identification, aerodynamic database, mathematical model

\section{NOMENCLATURE}

$\begin{array}{ll}\mathrm{AX}, \mathrm{AY}, \mathrm{AZ} & \text { Linear accelerations in body axis } \\ \mathrm{b} & \text { Wing span } \\ \bar{c} & \text { Mean aerodynamic chord } \\ \mathrm{CX}, \mathrm{CY}, \mathrm{CZ} & \begin{array}{l}\text { Nondimensional force coefficients } \\ \text { in X, Y and Z axis }\end{array} \\ \mathrm{Cl}, \mathrm{Cm}, \mathrm{Cn} & \begin{array}{l}\text { Coefficients of rolling, pitching and } \\ \text { yawing moments }\end{array} \\ C_{L}, C_{D}, C_{T} & \text { Lift, drag and thrust coefficients } \\ \mathrm{L}, \mathrm{M}, \mathrm{N} & \text { Roll, pitch and yawing moments } \\ \mathrm{M} & \text { Mach number } \\ \mathrm{Nz} & \text { Normal acceleration } \\ \mathrm{p}, \mathrm{q}, \mathrm{r} & \text { Roll, pitch and yaw rates } \\ \dot{p}, \dot{q}, \dot{r} & \text { Angular accelerations } \\ \bar{q} & \text { Dynamic pressure } \\ \mathrm{X}, \mathrm{Y}, \mathrm{Z} & \text { Aerodynamic forces in body axis } \\ \alpha & \text { Angle of attack } \\ \beta & \text { Angle of side slip } \\ \delta_{e}, \delta_{a}, \delta_{r} & \text { Elevon, aileron and rudder control } \\ \Delta C_{(.)} & \text {surface positions } \\ & \text { Incremental coefficients or } \\ c . g & \text { derivatives } \\ m r f & \text { Centre of gravity } \\ \mathrm{ADA} & \text { Moment reference point } \\ \mathrm{ADE} & \text { Aeronautical Development Agency } \\ & \text { Aeronautical Development } \\ & \text { Establishment } \\ & \end{array}$

${ }^{\dagger}$ Scientists, Flight Mechanics \& Control Division, CSIR, NAL, Bangalore

\#Scientists, Aeronautical Development Agency, ADA, Bangalore

$\begin{array}{ll}\text { GPS } & \text { Global Position System } \\ \text { RTS } & \text { Real Time Simulator } \\ \text { PID } & \text { Parameter Identification } \\ \text { FCS } & \text { Flight Control System }\end{array}$

\section{INTRODUCTION}

Tejas is a multi-role, supersonic, light combat aircraft, designed and developed by Aeronautical Development Agency (ADA) and HAL. Having attained Initial Operational Clearance (IOC) on $10^{\text {th }}$ January 2011 , it will be the mainstay of the Indian Air Force in the coming decades, meeting the stringent requirements expected of a frontline, multimission, tactical aircraft. It is a tailless, compound delta configuration with inherent longitudinal instability that makes it very agile and highly maneuverable. It is controlled by a highly reliable quadruplex fly-by-wire flight control system (FCS).

The aircraft is currently undergoing extensive flight test trails at the National Flight Test Centre (NFTC) in Bangalore. Bulk of this flight testing is directed towards gathering flight data from specially designed flight maneuvers for aerodynamic parameter identification studies (PID). This procedure of estimating aircraft stability and control derivatives, and validating/updating the wind tunnel aero database from flight data, has become an integral part of any aircraft development program [1]. Flight validated models are required not only for upgrading the aero database of the ground based simulators, but are also critical for safe flight envelope expansion. Since FCS is designed using linear models generated from the wind tunnel (or CFD) aero database, any modifications to the database would also require 
adjustments to FCS and a renewed stability analysis [2].

Contrary to the general practice of gathering data for PID on a single aircraft, flight test data on Tejas were collected on three different prototypes which made the identification task even more arduous. Flight testing was carried out for clean configuration as well as for combination of various external stores. Two identification approaches were used to analyze Tejas flight test data. The first approach, called the point model identification, is applicable to data from flight tests with relatively small deviations around the trim test points $[3,4]$. The second approach is more global in nature and is based on comparison of the wind tunnel aerodynamic force and moment coefficients with the flight derived aerodynamic coefficients [5-8]. This paper gives an overview of the two approaches with typical results from each of the techniques. Simulator to flight comparison showing improved time history matching after database update is also presented.

The following sections briefly examine the PID flight test planning, data compatibility process and the aerodynamic model identification approaches for Tejas flight test data analysis.

\section{FLIGHT TEST PLANNING}

For the Tejas aircraft, the test flight conditions were judiciously planned and the configurations and sequence of PID maneuvers to be flown for data gathering were carefully outlined to optimize the flight test effort. Flight data from PID maneuvers were gathered on PV2, PV3 and LSP2 aircraft upto Mach 1.3 and angle-of-attack $22 \mathrm{deg}$. These included flights for operational clean configuration (only R73 CCM) with airbrakes in and out, slats and undercarriage fully retracted / extended, and flights with various external store combinations.

The general procedure adopted for data gathering for point model identification was to trim the aircraft at selected test point in the flight envelope and apply control inputs to excite the aircraft modes of motion, taking care that the aircraft does not deviate too much away from the reference flight condition. Dynamic maneuvers like short period, bank-to-bank rolls, Dutch roll, rudder pedal and roll doublets in level flight, pull-up and push-over were flown for flight data generation [9].

For global model estimation using coefficient matching, data gathering was carried out from maneuvers generally used for performance evaluation, e.g., steady heading sideslip (SHSS), roller coasters, wind-up turns and accelerationdeceleration maneuvers. These maneuvers provide data over a larger range of angle-of-attack and angle of sideslip. Frequent interactions with the flight test team at NFTC, ADA helped to ensure high quality of PID data. Particularly demanding maneuvers were first practiced by the pilots in the RTS at ADE before carrying them out in actual flight.

\section{DATA COMPATIBILITY}

Inaccuracies in the raw flight test data can affect the convergence and accuracy of the estimates. Thus, one of the very important tasks is to do a data compatibility check (also known as flight path reconstruction or FPR), before using the data for model identification. Using kinematic equations, linear accelerations and angular rates were integrated to generate rigid body aircraft responses [9]. Output error method in time domain was used to estimate sensor biases, scale factors and inherent time delays in the measured signals. Scale factor errors for vane and side probe angles-of-attack (AoA) and sideslip were modeled as function of AoA to achieve the desired accuracy of less than 0.5 degrees in the flow angles. Figure 1 shows the reconstructed left and right vane AoA signals, and the residual error in AoA after correction. Wind velocities were estimated by incorporating GPS latitude and longitude data into the FPR process. The reconstructed trajectory was subsequently used for PID data analysis.

\section{PID PROCEDURE}

Two different approaches have been used for Tejas aerodynamic characterization from flight test data i) point model identification, and ii) coefficient level matching. A general idea of both is presented here in brief.

\subsection{Point Model Identification}

This approach yields linear derivative models for specific trim conditions in the flight envelope. Tejas aircraft being unstable in longitudinal axis, a stabilized output error method in time domain is used to prevent divergence during integration of the state equations [10]. The identified derivatives are compared with the stability and control derivatives obtained from the wind tunnel aero database.

Since this approach is applicable to flight data from only small amplitude maneuvers around specific trim points, a very limited portion of the flight envelope gets validated. Parts of the flight 
envelope, particularly those near the envelope boundaries where nonlinearities are predominant and therefore more critical for flight clearance, cannot be validated using this approach. Further, the use of estimated stability and control derivatives for update of the nonlinear aero database, which is in the form of lookup tables, is a nontrivial task.

To overcome these restraints, coefficient level matching concept was adopted which is applicable to all kinds of maneuvers in the entire flight regime.

\subsection{Coefficient Level Matching}

In this approach, total aerodynamic force and moment coefficients are extracted from flight data using measured angular rates and linear accelerations. This also requires additional information on aircraft mass, centre of gravity and inertias. The overall moments are transferred from the c.g to a specific reference point about which the aerodynamic model is to be developed. The flight derived coefficients are compared with total coefficients obtained from the baseline wind tunnel database and the difference " $\Delta$ " between the two sets of coefficients is minimized using equation error method to arrive at the incremental models for database update. An overview of the incremental model identification using coefficient level matching concept is shown in Figure 2.

A typical structure of incremental model for the moment coefficients is shown below.

$$
\begin{aligned}
\Delta \mathrm{Cm}= & \Delta \mathrm{Cm}_{0}(\mathrm{M})+\Delta \mathrm{Cm} \_\alpha(\alpha, \mathrm{M})+\Delta \mathrm{Cm} \_\delta \mathrm{e}(\mathrm{M}) \\
& +\Delta \mathrm{Cm}_{\mathrm{q}}(\mathrm{M}) \cdot \mathrm{q} \bar{c} / 2 \mathrm{~V} \\
\Delta \mathrm{Cl}= & \Delta \mathrm{Cl}_{0}(\alpha, \mathrm{M})+\Delta \mathrm{Cl}_{\beta}(\alpha, \mathrm{M}) \cdot \beta+\Delta \mathrm{Cl}_{\mathrm{p}}(\mathrm{M}) \cdot \mathrm{pb} / 2 \mathrm{~V} \\
& +\Delta \mathrm{Cl}_{\delta \mathrm{a}}(\mathrm{M}) \cdot \delta \mathrm{a} \\
\Delta \mathrm{Cn}= & \Delta \mathrm{Cn}_{0}(\alpha, \mathrm{M})+\Delta \mathrm{Cn}_{\beta}(\alpha, \mathrm{M}) \beta+\Delta \mathrm{Cn}_{\mathrm{p}}(\mathrm{M}) \cdot \mathrm{pb} / 2 \mathrm{~V} \\
& +\Delta \mathrm{Cn}_{\mathrm{r}}(\mathrm{M}) \cdot \mathrm{rb} / 2 \mathrm{~V}+\Delta \mathrm{Cn}_{\delta \mathrm{r}}(\mathrm{M}) \cdot \delta \mathrm{r}
\end{aligned}
$$

Each of the incremental models consists of effects due to aerodynamic bias, flow angles $\alpha$ and $\beta$, Mach number, angular rates and control surface deflections. Additionally, these increments in the force and moment coefficients also depend on the configuration flown, e.g., slat deflection, airbrake and under carriage position, etc. Other effects modeled into the estimation algorithm include i) inlet momentum effects as function of engine mass flow rate, and ii) change in aircraft cg as function of pitch angle.

The final incremental models identified from flight data are added to the baseline wind tunnel database to result in an updated model for full envelope on which validation studies are performed.

$$
\mathrm{C}_{\mathrm{j} \text {,updated }}=\mathrm{C}_{\mathrm{j} \text {,baseline }}+\Delta \mathrm{C}_{\mathrm{j}, \text { flight }}
$$

Where $\mathrm{j}=X, Y, Z, l, m, n$

\section{IDENTIFICATION RESULTS}

Selected results from point model identification and coefficient matching are presented in this section. The $\mathrm{X}$ and $\mathrm{Y}$ axis scales on some of the plots are concealed due to classified nature of the results.

\subsection{Results from Point Model Identification}

Weathercock Stability In Figure $3, \quad \mathrm{Cn} \beta$ derivative values obtained from the wind tunnel aero database are compared with the values obtained from flight test data analysis using point model identification, as a function of angle-of-attack. Note the limited coverage of AoA provided by the point model identification approach. It is evident that the values identified from flight are lower than those given by wind tunnel tests. These trends were subsequently confirmed from the repeat wind tunnel tests carried out with smaller step size in $\beta$ at Calspan.

Zero-Lift Drag Coefficient In order to estimate the lift and drag characteristics of Tejas aircraft, data gathering was carried out from several performance maneuvers, e.g., roller coasters, wind up turns and level acceleration/deceleration maneuvers. Flight data from these maneuvers were analyzed using output error estimation method. To determine $\mathrm{C}_{\mathrm{D} 0}$, the total drag coefficient in the estimation model was expressed as

$$
C_{D}=C_{D 0}+K C_{L}^{2}
$$

The values of zero-lift drag coefficient $\mathrm{C}_{\mathrm{D} 0}$ and efficiency factor $\mathrm{K}$ were estimated from flight data. Figure 4 shows the comparative plot of $\mathrm{C}_{\mathrm{D} 0}$ as a function of Mach number. At subsonic speeds, the $\mathrm{C}_{\mathrm{D} 0}$ estimates from flight seem to match quite well with the wind tunnel values. The rise in zero-lift drag at transonic speeds is well captured in flight. There is a discernible increase in the zero lift drag at supersonic speeds. Repeated analysis from a variety of maneuvers confirmed these trends at supersonic Mach numbers. The drag coefficient in the wind tunnel aerodata was subsequently updated to match with the flight estimated results. 


\subsection{Results from Coefficient Matching}

Pitch characteristics Using the coefficient matching approach, the difference $\Delta \mathrm{C}_{\mathrm{m}}$ between the wind tunnel and flight derived pitching moment coefficient was obtained for a set of maneuvers (nearly 30 to 40 ) covering a wide range of AoA for a given Mach, slat setting and aircraft configuration (e.g., clean or with external stores). The error in the pitching moment was plotted as a function of aircraft motion and control variables. Significant variations in $\Delta \mathrm{C}_{\mathrm{m}}$ were observed with AoA, as seen in Figure 5. Using incremental form of model structure discussed in section 4.2, a piecewise linear fit with appropriate placement of AoA breakpoints was utilized to estimate the nonlinearities in $\Delta \mathrm{C}_{\mathrm{m}}$. The aerodynamic bias term $\Delta \mathrm{Cm}_{0}$ was also estimated to obtain the final Cm update

$\mathrm{Cm}_{\text {, updated }}=\mathrm{Cm}$, baseline $+\left[\Delta \mathrm{Cm}_{0}(\mathrm{M})+\Delta \mathrm{Cm} \_\alpha(\alpha, \mathrm{M})\right]_{\text {flight }}$

No definitive trends were observed in $\Delta \mathrm{C}_{\mathrm{m}}$ with $\delta e$ or pitch rate $q$. Once the baseline model is updated, the difference between the flight $\mathrm{C}_{\mathrm{m}}$ and the updated $\mathrm{C}_{\mathrm{m}}$, for all practical purposes, is observed to be zero (see Figure 5). Comparison between the flight, preupdated and post-updated $\mathrm{Cm}$ time history for a typical pitch stick maneuver is shown in Figure 6. The significant improvement in the match between the flight and post-updated $\mathrm{Cm}$ in Figure 6 is clearly evident. This update helped to explain and resolve the significant reduction in turning performance of aircraft during flight testing in comparison to what was experienced in the simulator.

Weathercock stability The error $\Delta C_{n}$ between the wind tunnel and flight derived yawing moment coefficient was determined from a set of lateraldirectional maneuvers that included SHSS, roll stick and rudder pedal doublets in level flight and pull up, bank-to-bank maneuvers and wind up turns. This provided a wealth of data over a wide range of $\alpha$ from 0 to $22 \mathrm{deg}$ and $\beta$ from $-6 \mathrm{deg}$ to $+6 \mathrm{deg}$. Estimation of the fast derivatives was segregated from the static stability derivatives. For example, $\Delta \mathrm{Cn} \beta$ derivative was first estimated keeping $\Delta \mathrm{Cnr}$, $\Delta \mathrm{Cn} \delta \mathrm{r}$ and $\Delta \mathrm{Cn} \delta$ a fixed to zero. In the next step, if residual trends appeared in the plots of $\Delta \mathrm{Cn}$ with $\delta \mathrm{r}$, $\delta a$, yaw rate $r$ and roll rate $p$, estimation of the corresponding derivatives was taken up. This process of selective estimation avoided correlation between the derivatives thereby leading to more reliable incremental updates.
Figure 7 shows the comparative plots of $\operatorname{Cn} \beta$ obtained from original wind tunnel database and the updated database with incremental corrections for $\mathrm{Cn}$ included. The updated database shows reduced $\mathrm{Cn} \beta$ values, a trend commensurate with the results obtained from point model identification in Figure 3. In contrast to point model identification, the coefficient matching approach, however, yields derivatives over a wider range of AoA and the incremental corrections can easily be implemented into the baseline model to obtain updated aero database.

\section{VALIDATION VIA SIMULATION}

The final test for model fidelity is carried out by comparing the simulated responses from updated database with the flight measurements. To this end, a nonlinear simulation tool was developed that could be used to generate simulated time trajectories of the aircraft state variables both with the original and updated aerodynamic database. Flight measured pilot pitch/roll stick, pedal and throttle inputs were fed into the simulation. Information on c.g and flight configuration was provided into the tool and the simulation was initialized to match the non-steady initial conditions of the flight test maneuver.

Figure 8 shows the time history plots of the vertical acceleration, AoA and elevator control surface input for a segment of a roller coaster maneuver. The increase in the model fidelity of the updated database, as compared to the original database, is clearly evident.

\section{CONCLUSION}

A coordinated approach based on flight data gathering, mathematical modeling and system identification has been successfully used to generate nonlinear model updates for Tejas wind tunnel aerodynamic database. Flight test data from PID maneuvers spanning Mach range of 0.3 to 1.3 , AOA upto $22 \mathrm{deg}$ and sideslip of -6 to +6 deg have been analyzed to extract incremental models for operational clean configuration as well as external stores. Only selected results from point model identification and coefficient matching approach are presented in this paper. The effort has led to the development of high fidelity, flight-validated aerodynamic database of Tejas, resulting in safe expansion of flight envelope to IOC targets. 


\section{ACKNOWLEDGMENT}

The authors would like to thank Mr Shyam Chetty, Head, FMCD, NAL and PD-CLAW and Dr. Girish Deodhare, Assoc. PD-CLAW for their continuous support and encouragement. The authors would also like to acknowledge the teams from NFTC, AR\&DC, HAL and the ARD Group from ADA for their valuable inputs.

\section{REFERENCES}

1. Hamel, P.G and Jategaonkar, R.V, "Evolution of Flight Vehicle System Identification", Journal of Aircraft, Vol.33, No.1, pp 9-28.

2. Iliff, K.W., "Parameter Estimation for Flight Vehicles", J. of Guidance and Control, Vol.12, No.5, 1989.

3. Aksteter, J.W. et. al., "Parameter Identification and modeling of longitudinal aerodynamics," Journal of Aircraft, Vol. 32, No. 4, 1995, pp. 726-731.

4. Jategaonkar, R.V and Plaetschke, E., "Identification of moderately Nonlinear Flight mechanics Systems with Additive Process and Measurement Noise, J. of Guidance and Control, Vol.13, No.2, 1990.

5. Rohlf, D., "Direct Update of a Global Simulation Model with Increments via System identification", RTO Systems Concepts and Integration Panel (SCI) Symposium, Madrid, Spain, 5-7 May 1998.

6. Neville, K.W and Stephens A.T., "Flight Update of Aerodynamic Math Model", AIAA-93-3596-CP.

7. Rohlf, D., "Global Model Approach for X31 VECTOR System Identification", Journal of Aircraft, Vol.42, No.1, Jan-Feb 2005.

8. Bava, R., Hoare, G.T, Mesuro, G., Oelker, H.C., "Recent Experiences on Aerodynamic Parameter Identification for EUROFIGHTER at Alenia, British Aerospace, CASA and Daimler-Benz Aerospace", RTO Systems Concepts and Integration Panel (SCI) Symposium, Madrid, Spain, 5-7 May 1998.

9. J. R. Raol, Grija G. and J. Singh, Modeling and Parameter Estimation of Dynamic Systems, IEE Control Engineering Series 65, August 2004.

10. Jategaonkar, R.V and Thielecke, F., "Evaluation and Parameter Estimation Methods for Unstable Aircrafts, Journal of Aircraft, Vol.31, No. 3, May-June 1994, pp. 510-519

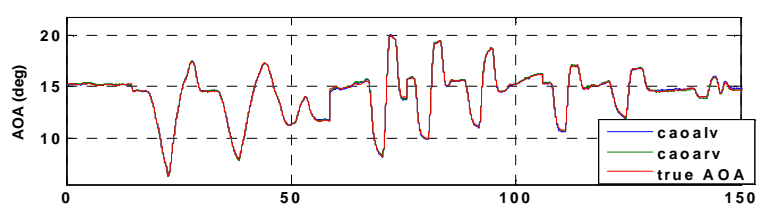

Figure 1(a). FPR generated left and right vane AOA vs. true AoA

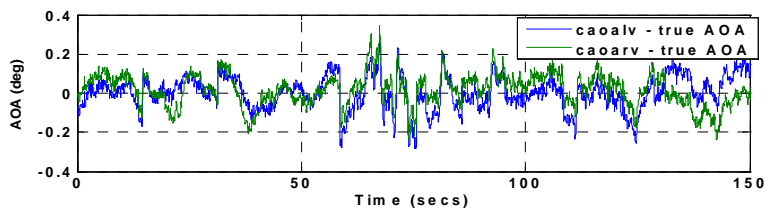

Figure 1(b). Plot showing vane AOA after FPR with error less than $0.3 \mathrm{deg}$

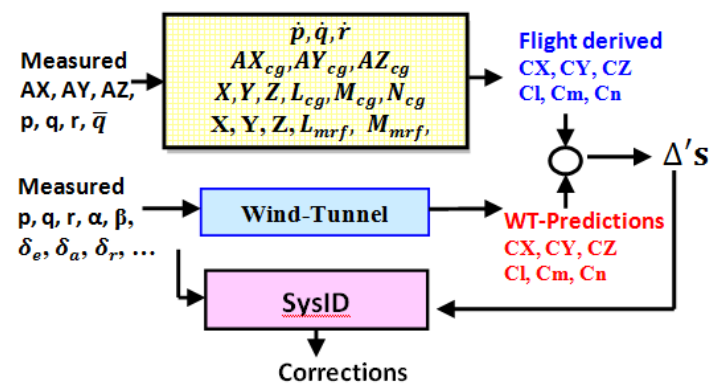

Figure 2. Incremental Model Identification based on Coefficient Level Matching

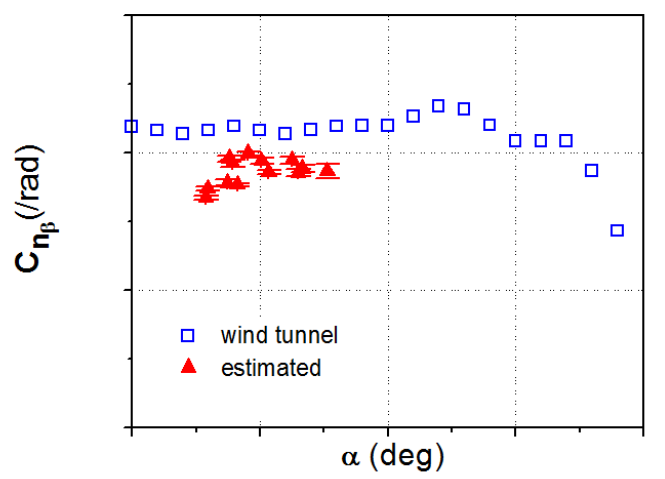

Figure 3. Directional stability derivative from point model Identification 


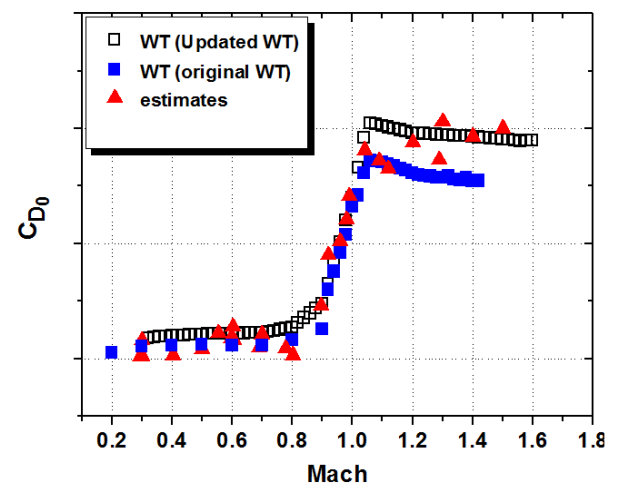

Figure 4. Zero lift drag vs. Mach number

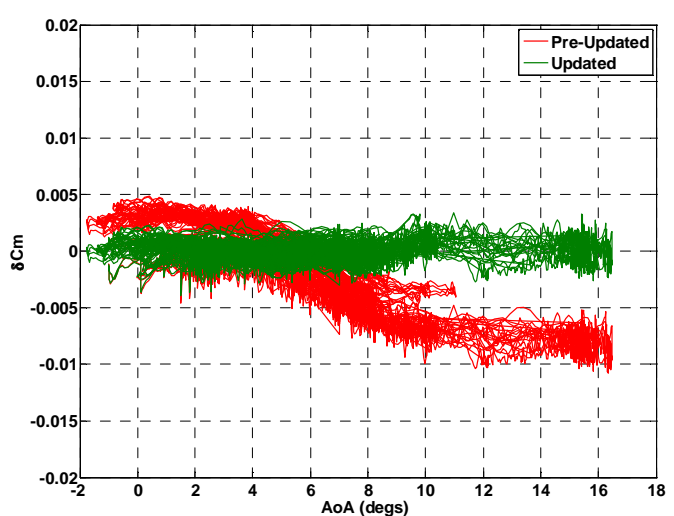

Figure 5. Error in pitching moment coefficient $\left(\Delta \mathrm{Cm}=\mathrm{Cm}_{\mathrm{WT}}-\mathrm{Cm}_{\mathrm{flt}}\right)$ before and after update

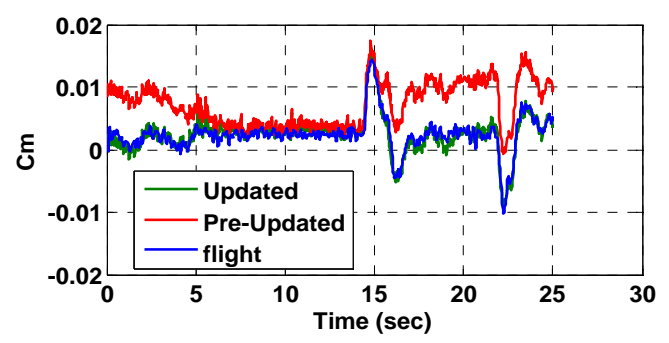

Figure 6. Cm time history match for a typical pitch stick maneuver before and after update

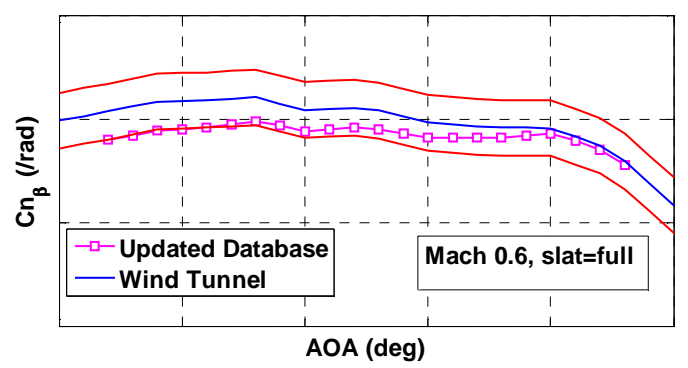

Figure 7. Updated Cnß obtained from coefficient matching approach
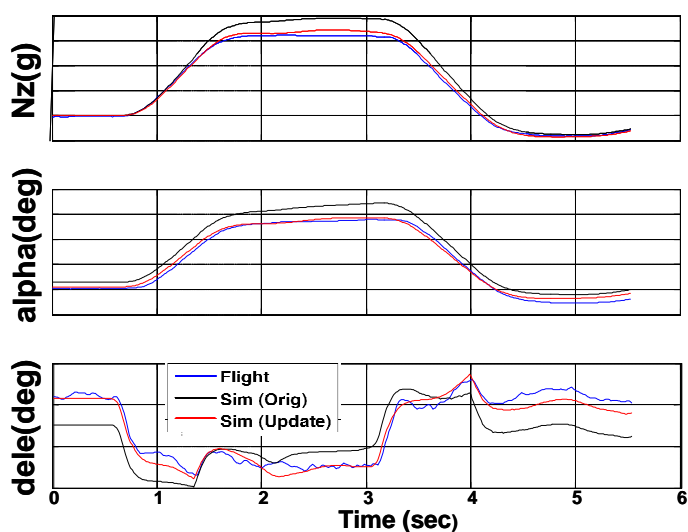

Figure 8. Time response match from validation run using 6DOF simulation (slats extended) 